\title{
Concept Maps: Integrating Knowledge and Information Visualization
}

\author{
Alberto J. Cañas, Roger Carff, Greg Hill, Marco Carvalho, Marco Arguedas, \\ Thomas C. Eskridge, James Lott, Rodrigo Carvajal \\ Institute for Human and Machine Cognition \\ Pensacola, FL 3202 USA \\ \{acanas, rcarff, ghill, mcarvalho, marguedas, teskridge, \\ jlott, rcarvajal\} aihmc.us \\ http://www.ihmc.us
}

\begin{abstract}
Information visualization has been a research topic for many years, leading to a mature field where guidelines and practices are well established. Knowledge visualization, in contrast, is a relatively new area of research that has received more attention recently due to the interest from the business community in Knowledge Management. In this paper we present the CmapTools software as an example of how concept maps, a knowledge visualization tool, can be combined with recent technology to provide integration between knowledge and information visualizations. We show how concept map-based knowledge models can be used to organize repositories of information in a way that makes them easily browsable, and how concept maps can improve searching algorithms for the Web. We also report on how information can be used to complement knowledge models and, based on the searching algorithms, improve the process of constructing concept maps.
\end{abstract}

\section{Introduction: Information and Knowledge Visualization}

Information visualization is a well-studied, broad topic. Since the earliest cave paintings, man has consistently pursued more effective and elegant ways of conveying information. More recently, advances in technology and in our understanding of cognition and perception have lead to new techniques and methods for visualizing information. Card et al. (1999) provided a comprehensive overview of research that has been done on the topic. Tufte $(1997,2001)$ wrote extensively on information design and demonstrated the maturity of the field. Workshops, symposiums, and conferences are frequently held on information visualization, for example, IEEE has an annual conference on the subject (e.g. IEEE, 2003).

Knowledge visualization, on the other hand, is a new field that is only recently receiving attention from the research and business communities. Burkhard and Meier (2004) defined knowledge visualization as the use of visual representations to transfer knowledge between at least two persons. From an Artificial Intelligence perspective, the knowledge engineering and knowledge representation communities for years have been primarily concerned with knowledge elicitation methodologies and the formal

Published in S.-O. Tergan, \& T. Keller, (Eds.) (in press). Knowledge and information visualization: Searching for synergies. Heidelberg / New York: Springer Lecture Notes in Computer Science. 
notation used to represent knowledge, and have dedicated little effort to visualization. The recent interest in Knowledge Management on the part of the business community (Becerra-Fernandez et al., 2003; Takeuchi \& Nonaka, 2004; Tiwana, 2000) has brought attention to the effective portrayal and sharing of knowledge, and awareness to the issue of knowledge visualization.

To distinguish between information and knowledge visualization, we first need to distinguish between information and knowledge, a differentiation that is not always straightforward. Typical distinctions between them in the Knowledge Management literature are not of much use. They are either inadequate for our purposes as in "Knowledge is bigger than information" (Grayson \& O'Dell, 1998) and "Knowledge is information in action" (ibid), or just plain wrong: "Our organizations are awash in information, but until people use it, it isn't knowledge" (ibid), I may be knowledgeable about a subject and never use that knowledge - is it then not knowledge?). Tiwana (2000) referred to knowledge as "... a fluid mix of framed experience, values, contextual information, expert insight and grounded intuition that provides an environment and framework for evaluating and incorporating new experiences and information. It originates and is applied in the mind of knowers." Encyclopedia definitions are not of much help either: "Knowledge is distinct from simple information. Both knowledge and information consist of true statements, but knowledge is information that has a purpose or use." (Knowledge, 2004, November 21). These definitions don't really tell us what knowledge is. For the purpose of this paper, we will provide a pragmatic distinction between knowledge visualization and information visualization. But first we must present our understanding of what "knowledge" is, and introduce the concept map as a knowledge visualization tool.

Our interpretation of "knowledge" is based on the theories of knowledge and learning from Ausubel et al. (1978) and Novak (1977) on which our research is supported. Novak (ibid) proposed that the primary elements of knowledge are concepts and relationships between concepts called propositions. Concepts are defined as "perceived regularities in events or objects, or records of events or objects, designated by a label" (Novak, 1998). Propositions consist of two or more concept labels connected by a linking relationship that forms a semantic unit (Novak \& Gowin, 1984). Most researchers agree that knowledge is a human creation. Using these propositions, we construct new knowledge by linking new concepts to knowledge we already have. Knowledge is constructed through meaningful learning (in contrast to rote learning or memorization), which takes place when the learner deliberately seeks to relate and incorporate new information to relevant knowledge he/she already possesses (Ausubel et al., 1978).

\section{Concept Map: A Knowledge Visualization Tool}

Novak and Gowin's (1984) research into human learning and knowledge construction led to the development of Concept Maps: a graphical tool that enables anybody to express their knowledge in a form that is easily understood by others. Concept Maps are a graphical two-dimensional display of knowledge that is comprised of concepts (usually represented within boxes or circles), connected by directed arcs encoding 
brief relationships (linking phrases) between pairs of concepts. These relationships usually consist of verbs, forming propositions or phrases for each pair of concepts. The simplest concept map would consist of two nodes connected by an arc representing a simple sentence such as 'grass is green,' but they can also become quite intricate. Figure 1 shows a concept map about concept maps by Novak (2003). 'Concept Maps represent Organized Knowledge' is one of the propositions of this map. 'Organized Knowledge is comprised of Concepts' and 'Organized Knowledge is comprised of Propositions' are two other propositions. By convention, links run top-down unless annotated with an arrowhead. The vertical axis expresses a hierarchical framework for the concepts. More general, inclusive concepts are found at the highest levels, with progressively more specific, less inclusive concepts arranged below them.

The structure of a concept map is dependent on its context. Consequently, maps having similar concepts can vary from one context to another and are highly idiosyncratic. The strength of concept maps lies in their ability to measure a particular person's knowledge about a given topic in a specific context. Therefore, concept maps constructed by different persons on the same topic are necessarily different, as each represents its creator's personal knowledge. Similarly, we cannot refer to the correct concept map about a particular topic, as there can be many different representations of the topic that are correct.

Concept mapping techniques have helped people of all ages examine many fields of knowledge. When concepts and linking words are carefully chosen, these maps are powerful tools for observing nuances of meaning. Their rich, expressive power derives from each map's ability to allow its creator to use a virtually unlimited set of linking words to show how meanings have been developed. There are no restrictions

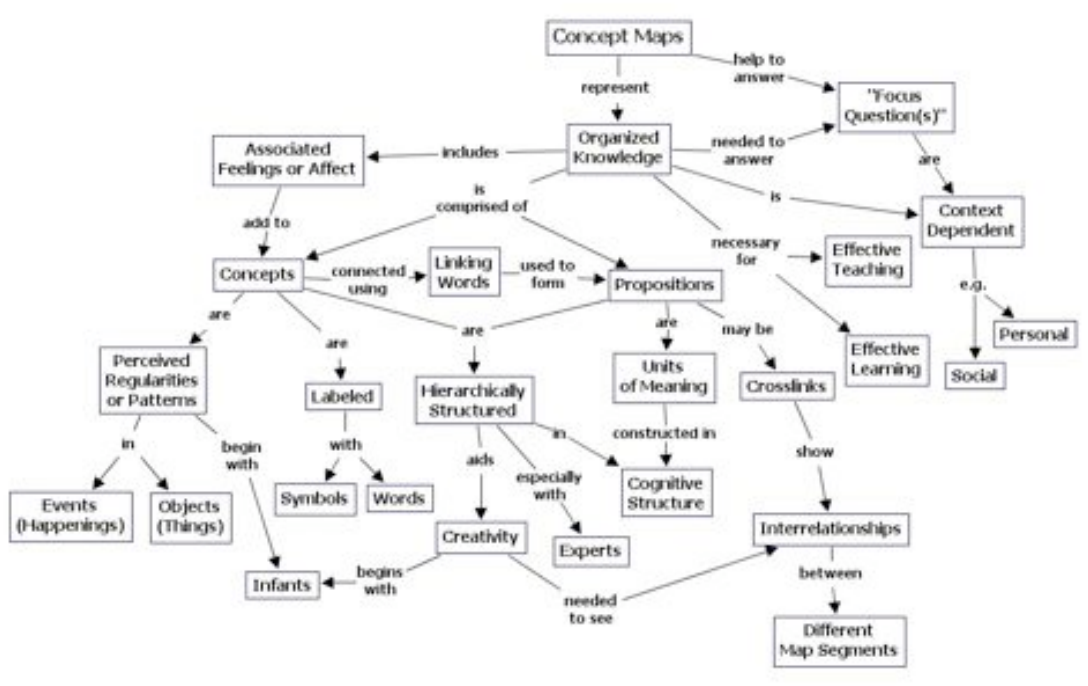

Fig. 1. Concept map about concept maps (Novak, 2003) 
on what words can be used to form concepts or linking phrases. Concepts tend to be nouns and linking phrases are usually verbs, and it is recommended that both consist of as few words as possible. Linking phrases can express any type of relationship, and are not limited to a defined set (e.g., is-a, part-of, etc.) as in other diagramming techniques such as semantic networks. However, it is this freedom in the construction of linking phrases in particular that prevents concept maps from being automatically translatable to any formal representation.

In a "well constructed" concept map,

1. Each pair of concepts, together with their joining linking phrase, can be read as an individual statement or proposition that makes sense. Hoffman et al. (2005) referred to a concept map where all the triples (concept, linking phrase, concept) are well-formed propositions, as being propositional coherent. In addition, in well constructed concept maps:

2. Concepts and linking phrases are as short as possible, possibly single words.

3. The structure is hierarchical and the root node of the map is a good representative of the topic of the map.

Concept maps have been demonstrated to be an effective means of representing, visualizing, and communicating knowledge. From an education perspective, there is a growing body of research that indicates that the use of concept maps can facilitate meaningful learning (Coffey et al., 2003a). During concept map construction, meaning making occurs as the learner makes an effort to link the concepts to form propositions. The structure of these propositions into a map is a reflection of his/her understanding of the domain. Mapping techniques are employed to help students "learn how to learn" by bringing to the surface cognitive structures and self-constructed knowledge (Novak \& Gowin, 1984).

Concept maps have also proven to be valuable as a knowledge acquisition tool during the construction of both expert systems (Ford et al., 1996) and performance support systems (Coffey et al., 2003b), and as a means for capturing and sharing experts' knowledge (Coffey et al., 2002). The results of these elicitation and modeling efforts are browsable knowledge models that visually represent the knowledge of the experts. Figure 2 shows a screen capture of the STORM-LK ${ }^{1}$ system (Hoffman et al., 2000). It illustrates a collection of concept maps and associated media (video, satellite image, and a text Web page) that visually represent the knowledge needed for weather forecasting in the Gulf of Mexico, as elicited from experts from the U.S. Navy's Meteorology and Oceanography Command (METOC) in Pensacola, FL.

The sample concept maps and associated media shown in Figure 2 lead us to our distinction between knowledge and information visualization. For the context of this paper, we regard the concept maps to be the visualization of knowledge, and all other media (images, videos, text, sound, charts, etc.) to be the visualization of information. We understand that some of the associated media (e.g., text) may depict knowledge, but this distinction will simplify the discussion of how concept maps can be used to integrate knowledge and information visualization.

${ }^{1}$ The STORM-LK model can be browsed at http://www.ihmc.us/research/projects/StormLK/ 


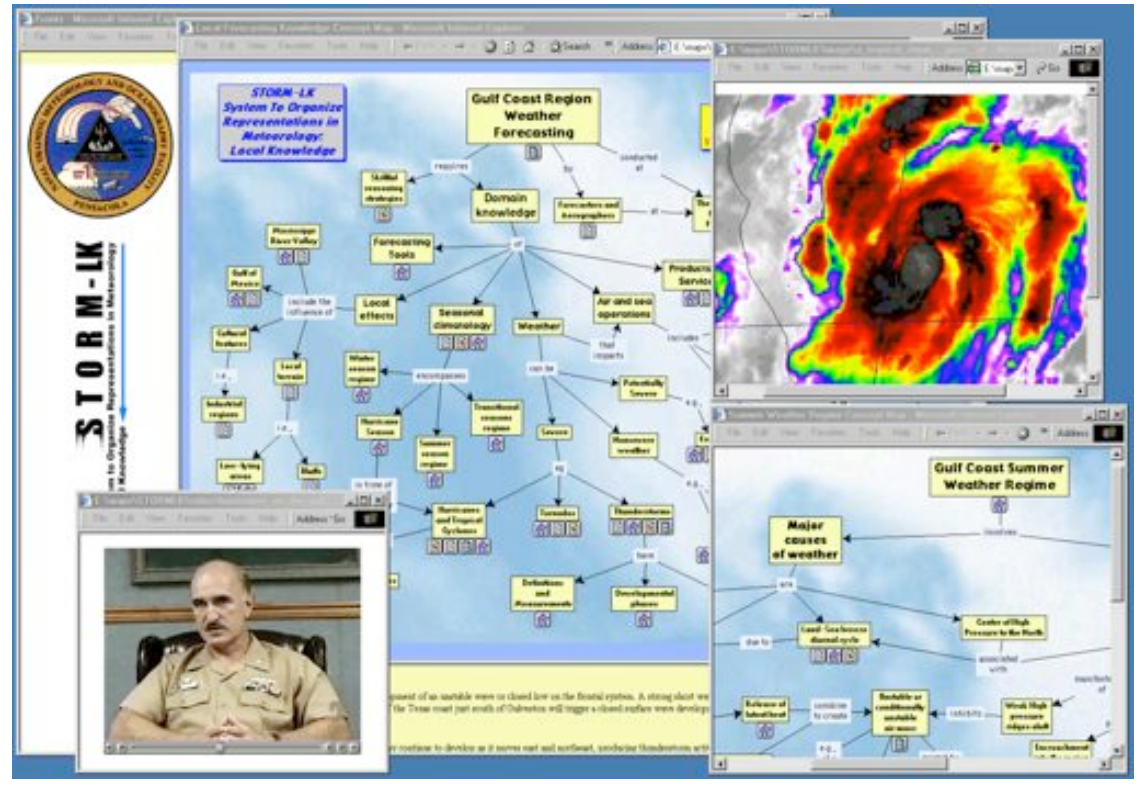

Fig. 2. A screen shot from STORM-LK, a browsable visual model of weather forecasting expertise (Hoffman et al., 2000).

\section{Integration of Knowledge and Information Visualization}

Traditionally, concept maps have been used primarily as a tool for students to demonstrate their understanding of a topic so that teachers could evaluate them. Early software programs for concept mapping mimicked this behavior, allowing students to construct a map, save it, and print it. In some cases, the possibility of including colors, shapes, and links to resources located on the student's computer, were added. However, it is the integration of concept mapping with information resources (Cañas et al., 1994; Ford et al., 1993) and the later development of the Web that has generated a new role for concept maps as a knowledge visualization tool, thus creating the possibility of integrating knowledge visualization and information visualization. In the rest of this paper we provide examples of such integration.

\subsection{CmapTools: A Knowledge Modeling and Sharing Environment}

Concept maps are an effective way to visually represent a person's understanding of a domain of knowledge. Technology can further help by making it easy to construct and 
modify these representations, to manage large representations for complex domains, to integrate knowledge and information to create knowledge models, and to allow groups of people to share in the construction of the concept maps. CmapTools ${ }^{2}$ (Cañas et al., 2004b) is a software environment developed at the Institute for Human and Machine Cognition that empowers users, individually or collaboratively, to represent their knowledge using concept maps; to link media resources to them, to share them with peers and colleagues, and to publish them.

Public servers have been established to encourage and support the publishing and sharing of knowledge by users of all ages from anywhere on the Internet (Cañas et al., 2004b, 2003a). On these CmapServers (e.g., IHMC Public Cmaps), using the CmapTools client program, any user can create his/her own folder and publish a concept map and associated resources.

The user interface and functionality of CmapTools have been designed to be simple enough to be apt for children and naïve users without much technical expertise, but powerful enough to support the advanced needs of expert knowledge engineering users. As a result, thousands of users are constructing knowledge models based on concept maps and sharing them through the public CmapServers.

\subsection{CmapTools: Integrating Knowledge and Information Visualization}

In CmapTools, we have extended the use of concept maps beyond knowledge representation, to serve as the browsing interface to a domain of knowledge and associated resources (Cañas et al., 1994; Ford et al., 1993). In the case of a large domain, or of a detailed representation of a domain, a single concept map can become unmanageable for the user to comprehend, display, and manipulate. To facilitate the construction of large representations, CmapTools allows the user to split them into collections of concept maps. To show the relationships between the concept maps in the set, the software facilitates the linking of concept maps, enabling the navigation from one concept map to another. Additionally, the user can establish links to other types of resources (e.g., images, videos, sound clips, text, Web pages, documents, presentations, and other concept maps) that help explain and complement the information in the map.

In CmapTools, a set of concept maps and associated resources about a particular domain of knowledge is referred to as a "knowledge model" (Cañas et al., 2003b). Figure 3 shows several opened windows, the result of navigating through the CMEX (NASA's Center for Mars Exploration) knowledge model about Mars (Briggs et al., $2004)^{3}$. The "Mars" concept map in the figure is the top-level map, the entry point to this knowledge model. Some concepts in the "Mars" concept map have small icons underneath them. These icons indicate that there are other resources (e.g., images, text, videos, Web pages, other concept maps) that contain additional information, refer to, or further explain that particular concept. By clicking on the "concept map" icon underneath a concept, a list of available concept maps is displayed, which the

2 The CmapTools software is available free for educational and non-profit use from http://cmap.ihmc.us.

${ }^{3}$ The CMEX Mars model can be browsed at http://www.cmex.arc.nasa. 


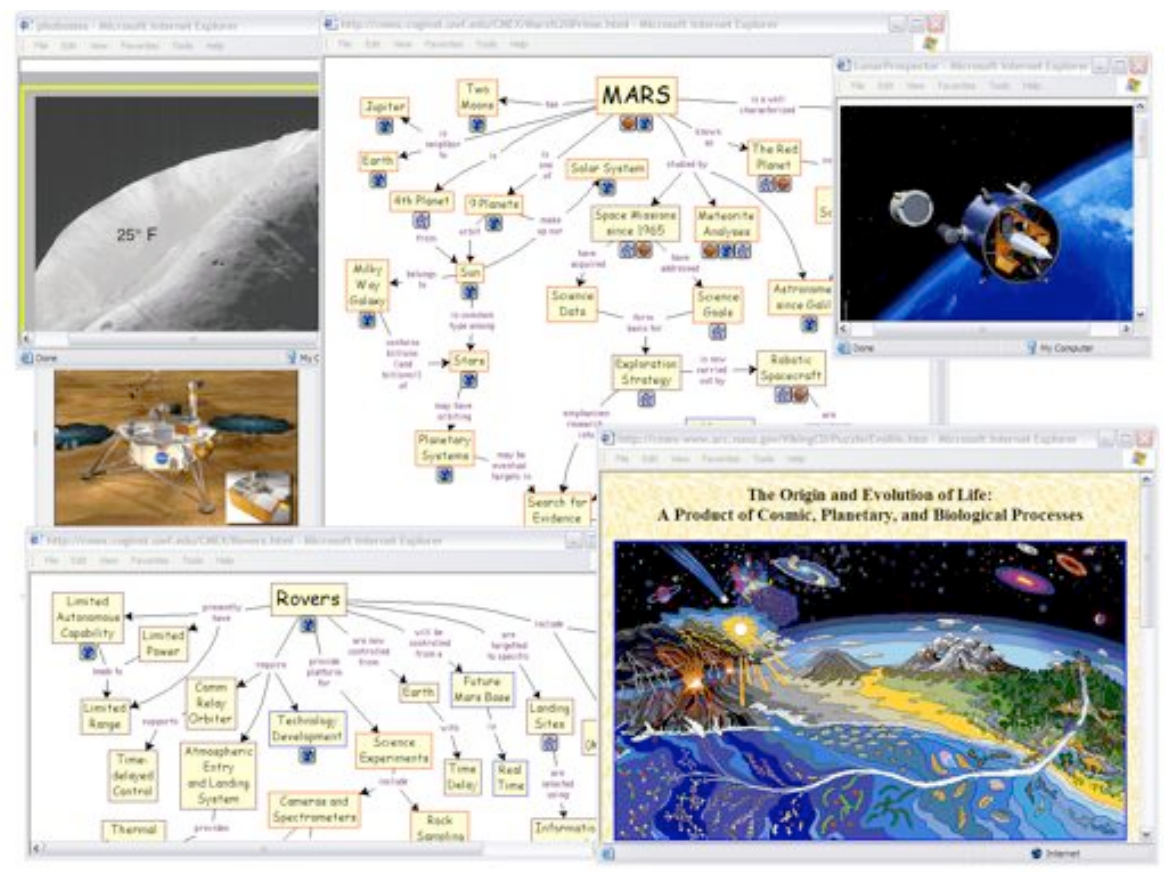

Fig. 3. The CMEX knowledge model on the Mars domain consists of over 100 linked concept maps and over $600 \mathrm{MBs}$ of resources.

user can select and open. For example, by clicking on the "concept map" icon underneath the "Exploration Strategy" concept, from the list of concept maps displayed, the user can select and open a "Mars Exploration Strategy" concept map (not displayed in Figure 3). In this concept map, a concept labeled "Robotic Exploration" has a "concept map" icon that leads to a "Space Missions to Mars" concept map (not displayed in Figure 3); The "Space Missions to Mars" concept map has a "concept map" icon that leads to the "Rovers" concept map shown in Figure 3. The other images shown are opened by a similar navigation through the icons in the concept maps.

The CMEX Mars knowledge model consists of over 100 concept maps that are used as a means to browse and search through over $600 \mathrm{MBs}$ of resources of all types. The concept maps become the navigational tool with which the user navigates through this particular domain of knowledge, thereby integrating the "knowledge" and "information" representations. These concept maps are mainly used as a means to help the user to locate the information of interest. The concepts act as a set of "categories" from which the user selects during his/her navigation effort, whereas the linking phrases help by explaining how these "categories" are related: They reduce the "variability" between these categories (Cañas, 1985). Geoffrey Briggs, Director of CMEX and an expert on Mars, constructed the CMEX Mars maps, and his deep understanding of the domain led to an easy to navigate set of maps. They were constructed with the purpose of being a navigational aid, not as a means for the expert to convey his complete understanding of the topics in the maps. The in-depth descriptions of the 
topics are found in the associated resources. Using concept maps as a means to organize large repositories of media and as a browser for navigation through a large domain is particularly effective, as discussed by Carnot et al. (2001).

The STORM-LK maps, in contrast, are much more "dense" in terms of the number of propositions they contain. The maps are meant to represent the experts' knowledge, whereas the associated media are intended to complement the knowledge in the maps.

The two knowledge models demonstrate different types of integration between knowledge and information. In the CMEX Mars model, the concept maps are the organizing and browsing mechanism to a large collection of information represented in a variety of media. In STORM-LK, the media complements the expert's knowledge represented in the concept maps. The type of integration is determined by the purpose of the knowledge model.

\section{Searching and Mining the Web from Concept Maps}

Search engines have become a hot topic as the Web grows into what a few years ago was an unimaginable size. The act of Web browsing has been replaced lately with large-scale search engines. Nobody "surfs" the Web any more: Users "Google" into the topic they are interested in and then leave. That is, many Web users rely on the large-scale server farm to index billions of Web pages for them.

To retrieve relevant Web pages, search engines rely on the query specified by the user, but users rarely provide a "good" query: The average search query, from a recent study, is 2.2 words (Spink et al., 2001). As a result, the list of retrieved documents is often too large or contains information that has no relevance to the query. We propose to alleviate this problem by taking advantage of the context provided by concept maps to both (a) provide more complete queries to the search engines, and (b) enhance the ranking of the results provided by the engines. Additionally, we leverage on this concept map-based search to aid users in the construction of their concept maps. These tools provide another level of integration between knowledge representations and large repositories of information.

To achieve these goals, we take advantage of the semantic and topological characteristics of concept maps. We have found that following Novak and Gowin's (1984) guidelines in terms of making concepts single words and linking phrases as short as possible leads to concept maps that, although not readily translatable to a more formal notation, provide an abundance of information that can be taken advantage of by smart tools (Cañas \& Carvalho, 2004) that can search and mine the Web. In addition, these tools take advantage of the particular characteristics of concept maps.

1. Concept maps have structure: By definition, concept maps tend to have a hierarchical structure where more general concepts are presented at the top and more specific concepts at the bottom. Additionally, other structural information, for example, the number of ingoing and outgoing links of a concept, may provide additional information regarding a concept's role in the map. (Leake, Maguitman, \& Reichherzer, 2004a, presented experimental support for the cognitive importance of such factors.) 
2. Concept maps are based on propositions: Every two concepts along with their linking phrase form a "unit of meaning." This propositional structure distinguishes concept maps from other tools such as Mind Mapping and The Brain, and provides semantics to the relationships between concepts.

3. Concept maps have a context: A concept map is a representation of a person's understanding of a particular domain of knowledge. As such, all concepts and linking phrases are to be interpreted within that context.

\subsection{Searching the Web from a Concept Map}

By allowing users to search the Web from a concept map, CmapTools provides another type of integration between knowledge and information representations. The user constructs a visual knowledge representation as a concept map and CmapTools takes this as the basis for the search, retrieving information that is relevant to the map.

The user can easily and concisely specify the context of the search in a concept map, which will be used for the automatic construction of queries. The Web-search algorithm implemented in CmapTools allows the user to select a concept and ask the system to search for Web information that is relevant to the concept within the context of the concept map. The process consists of (a) analyzing the concept map to prepare a relevant query to use in searching the $\mathrm{Web},(\mathrm{b})$ retrieving relevant documents from the Web, (c) ranking the retrieved Web pages according to relevance, and (d) presenting the results to the user. Each of these steps is described briefly below, though a more detailed explanation can be found in Carvalho et al. (2001). To generate the query, key concepts are selected from the map. These include the words in the selected concept itself, the root of the concept map, and the authority nodes: those with the highest number of outgoing links to other nodes. We assume that the number of outgoing links is indicative of further elaboration of these concepts, and therefore, a gauge of their relevance in the context of the map. We use the query constructed from the key concepts in the previous step to retrieve Web pages and build our collection of documents. We have developed a metasearch engine, based primarily on Google (Brin \& Lawrence, 1998), in order to retrieve an initial set of documents from the public Web. Once retrieved, these documents are added to a local cache for ranking, which is based on comparing distance matrices calculated from the concept map and from each of the candidate documents. The distance matrices are symmetric, and provide a weighted list of the concept terms in the map and the documents. Weights between terms in the concept map are proportional to the number of linking phrases between each concept. For the documents, the weights are estimated as a function of the number of words between each concept map term found in the text. Lower distances between terms represent a higher weight, as terms are more likely to form a proposition. 
Experimental results reported in Carvalho et al. (2001) showed that the algorithm scored similarly or better than the best of four publicly available search engines in ranking retrieved documents for relevance to the concept map according to the subjects' criteria, and clearly performed better than the other three. The combination of leveraging on the structure of the concept map in generating the query, and utilizing the propositional nature and hierarchical topology of concept maps to provide contextual information to identify and rank retrieved documents that are more relevant, seems to provide an improvement over the ranking provided by publicly available search engines. Figure 4 shows the result of performing a search on the concept "Propositions" within the context of the concept map from Figure 1. The retrieved list of Web pages shows how relevant results are obtained by leveraging on the concept map to perform the search.

\subsection{Mining the Web to Aid Concept Map Construction}

CmapTools' Web search capabilities can also aid the user in the process of building a

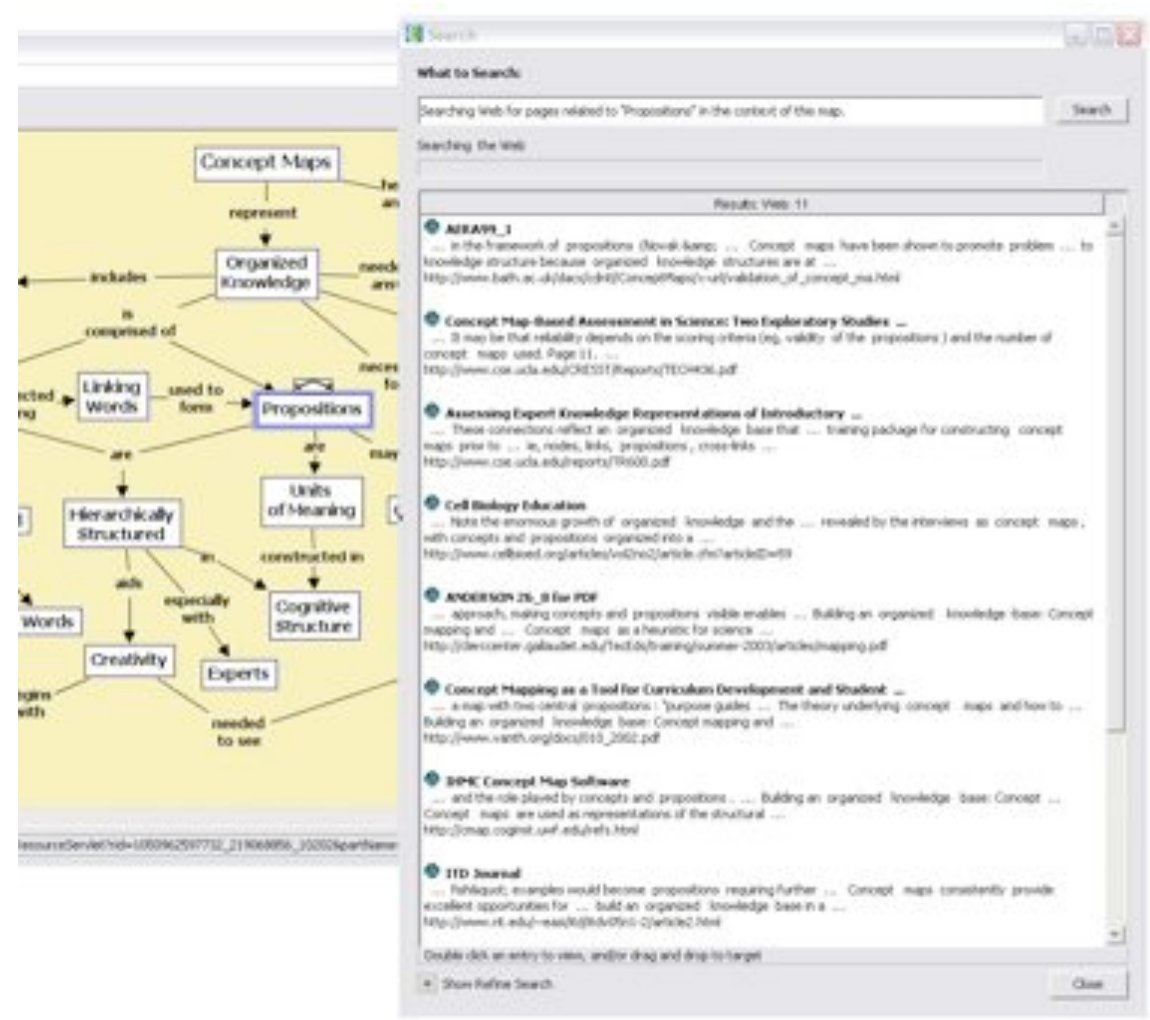

Fig. 4. Result of performing a Web search from the map in Figure 1 on the concept "proposition" shows a retrieved list of Web pages that are relevant to the term in the context of the concept map. 
concept map. The CmapTools application proactively monitors the context of an open concept map to autonomously search for Web information that could be relevant to the user. At the user's discretion, this information can be utilized to verify, correct, or extend his/her concept maps during browsing or authoring. From the point of view of knowledge and information integration, the information from the Web aids the user in the construction of knowledge representations.

This capability is integrated with the editor, and Web-based suggestions can be provided in two forms, namely a) a list of relevant Web-pages that can be used as references by the user, or b) a list of relevant concepts that the user can, at his/her discretion, add to the concept map to broaden or clarify the content. This information is proactively offered by the application as the map context changes, but it can also be requested on-demand by the user.

The suggestion of Web pages is based on an enhanced version of the search algorithm used to obtain relevant pages from the Web, based on the current stage of the concept map (Leake et al., 2004b). A key difference in the proactive suggestion of Web pages is that the whole map is taken into account. This is in contrast to the ondemand search, where the user is allowed to specify a concept within the map that is used to focus the search.

CmapTools can also suggest "concepts" during the construction of a map. Concept map construction is a meaning-making process in which listing the concepts that will be included in the map is a less central task than selecting the appropriate linking phrase to form propositions. Often, however, we have found that users struggle to "remember" new concepts to add to their maps, and we believe that they should be able to concentrate their efforts on determining the linking phrases between concepts in the map. We have implemented in the CmapTools software a proactive concept suggester (Cañas et al., 2004a) module which, during map construction, analyzes the concept map, creates a relevant query to search the Web for documents related to the map, extracts relevant concepts from the retrieved Web pages, and presents the results as suggestions to the user. This module searches for new suggestions whenever it determines that the map has suffered significant changes.

Cañas et al. (2004a) described tests of this module with a group of users, and reported that their results indicate that the module is effective in presenting relevant concepts to the users. This effectiveness, however, diminishes as the map grows, which implies that the algorithm should be revised to take into account that in larger maps, users are most likely working on a piece of the map, and suggested concepts should be determined by the context of that piece. Figure 5 shows the list of concepts suggested by CmapTools for the concept map about concept maps in Figure 1. Observe that "Novak" is one of the suggested concepts - the inventor of concept mapping should be part of the concept map about concept maps.

The search and mining mechanisms show how we can take advantage of the particularities of "knowledge" and "information." The characteristics of the visual representation of knowledge in the form of a concept map provides the possibility of generating "smart" queries that lead to improved retrieval from large information repositories, for example, the Web. Taking this feature one step further, mining the Web from these queries allows CmapTools to take advantage of the abundance of information on the Web to suggest to the user "concepts" and "Web pages" that can be used to improve the map under construction. 


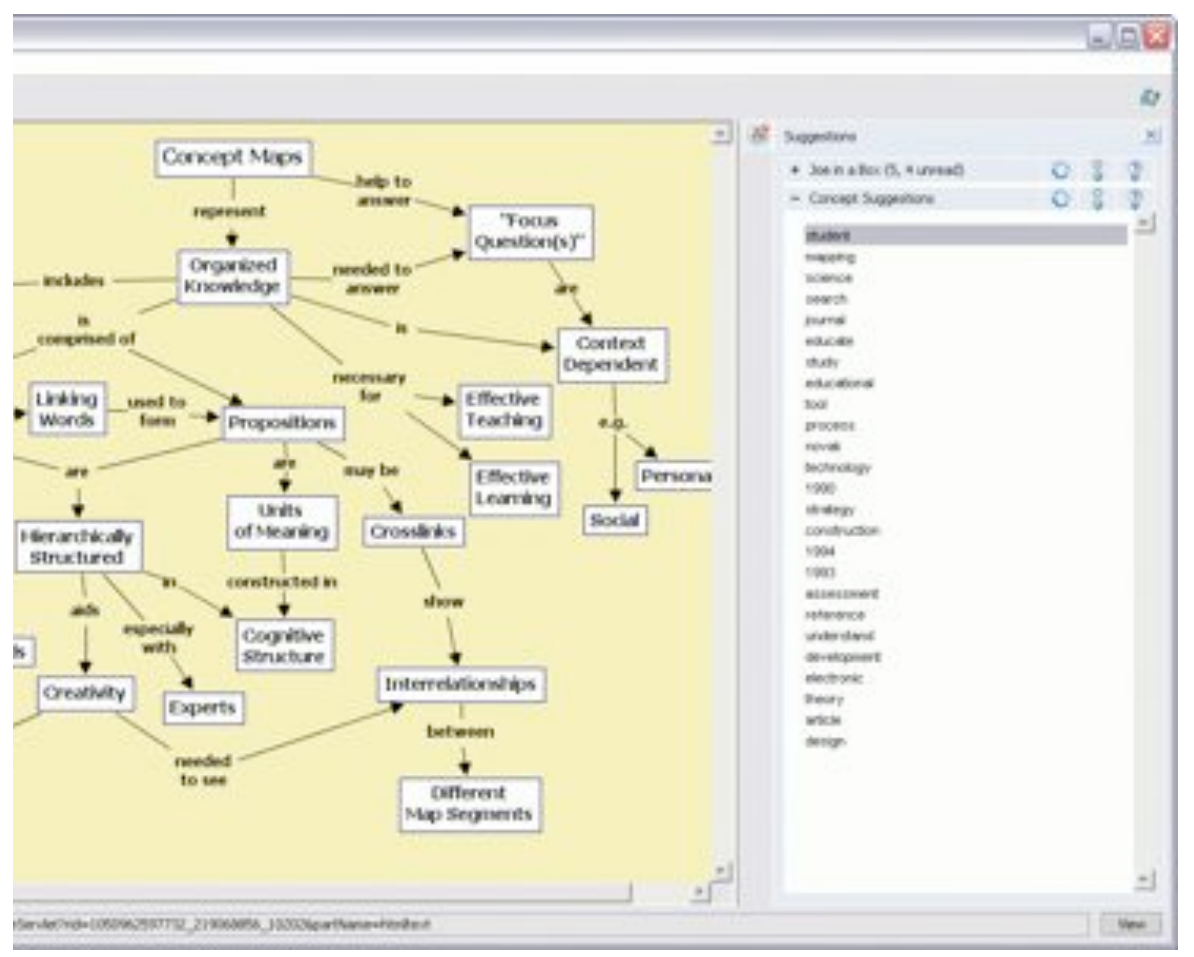

Fig. 5. List of concepts suggested for the concept map in Figure 1. Observe that "Novak" is one of the concepts suggested.

\section{Prospects and Perspectives}

Knowledge visualization techniques bring new approaches to an already mature field of information visualization. Leveraging on modern computer-based mapping tools and the Internet, an integration of knowledge and information visualization has the potential of impacting the management of knowledge, information, and education in a variety of contexts, among them self-regulated resource-base learning (Coffey \& Cañas, 2003), sense-making information visualization, and cross-community knowledge and information exchange (Novak et al., 2002). The attention that knowledge visualization is receiving from the business community in the context of knowledge management brings both commercial and research opportunities. Commercial, since corporations are carefully analyzing how a better elicitation, representation and administration of their knowledge can give them a competitive advantage. Research, because there is still a long research path to follow before we fully comprehend how to "manage knowledge."

Concept mapping, a technique that has been around in the education arena for close to thirty years, has shown to be an effective technique for representing knowledge. A 
rationale for using concept maps for managing knowledge and knowledge resources has been presented by Tergan (2003) and is outlined by Tergan in more detail In this book. In this paper we have shown that with CmapTools -a concept map-based knowledge modeling and sharing software environment- knowledge models can be used to organize large repositories of information and to provide an effective navigational tool. Moreover, information in the form of diverse media types can be used to complement the knowledge in the concept maps. We have also described how, by taking advantage of the particular topological and semantic characteristics of concept maps, knowledge models can be used to construct a search environment that improves on the results of commercial search engines, and takes advantage of the large amounts of information contained by these search engines to aid users during the construction of concept maps. We believe, and propose that, as better tools are developed that take advantage of the characteristics of concept maps, further integration and synergies between knowledge and visualization tools will emerge.

\section{References}

Ausubel, D. P., Novak, J. D., \& Hanesian, H. (1978). Educational psychology: A cognitive view (2nd ed.). New York: Holt, Rinehart and Winston.

Becerra-Fernandez, I., Gonzalez, A., \& Sabherwal, R. (2003). Knowledge management challenges, solutions, and technologies. Upper Saddle River, NJ: Prentice Hall.

Briggs, G., Shamma, D. A., Cañas, A. J., Carff, R., Scargle, J., \& Novak, J. D. (2004). Concept maps applied to Mars exploration public outreach. In A. J. Cañas, J. D. Novak \& F. González (Eds.), Concept maps: Theory, methodology, technology. Proceedings of the first international conference on concept mapping (Vol. I, pp. 109-116). Pamplona, Spain: Universidad Pública de Navarra.

Brin, S., \& Lawrence, P. (1998). The anatomy of a large-scale hyptertextual web search engine. Computer Networks, 30(1-7), 107-117.

Burkhard, R., \& Meier, M. (2004). Tube map: Evaluation of a visual metaphor for interfunctional communication of complex projects. Paper presented at the I-KNOW '04, Austria.

Card, S. K., Mackinlay, J. D., \& Shneiderman, B. (1999). Readings in information visualization: Using vision to think. San Francisco, CA: Morgan Kaufmann Publishers.

Carnot, M. J., Dunn, B., Cañas, A. J., Graham, P., \& Muldoon, J. (2001). Concept maps vs. Web pages for information searching and browsing. from http://www.ihmc.us/users/acanas/Publications/CMapsVSWebPagesExp1/CMapsVS WebPagesExp1.htm

Carvalho, M. R., Hewett, R., \& Cañas, A. J. (2001). Enhancing web searches from concept map-based knowledge models. In N. Callaos, F. G. Tinetti, J. M. Champarnaud \& J. K. Lee (Eds.), Proceedings of SCI 2001: Fifth multiconference on systems, cybernetics and informatics (pp. 69-73). Orlando, FL: International Institute of Informatics and Systemics.

Cañas, A. J. (1985). Variability as a measure of semantic structure in document storage and retrieval. University of Waterloo, Waterloo, Ontario.

Cañas, A. J., \& Carvalho, M. (2004). Concept maps and AI: An unlikely marriage? In Proceedings of SBIE 2004: Simpósio brasileiro de informática educativa. Manaus, Brasil: SBC.

Cañas, A. J., Carvalho, M., Arguedas, M., Leake, D. B., Maguitman, A., \& Reichherzer, T. (2004a). Mining the web to suggest concepts during concept map construction. In A. 
J. Cañas, J. D. Novak \& F. M. González (Eds.), Concept maps: Theory, methodology, technology. Proceedings of the 1st international conference on concept mapping. (Vol. I, pp. 135-142). Pamplona, Spain: Universidad Pública de Navarra.

Cañas, A. J., Ford, K. M., \& Coffey, J. W. (1994). Concept maps as a hypermedia navigational tool. Paper presented at the Seventh Florida Artificial Intelligence Research Symposium (FLAIRS), Pensacola, FL.

Cañas, A. J., Hill, G., Carff, R., Suri, N., Lott, J., Eskridge, T., Gómez, G., Arroyo, M., \& Carvajal, R. (2004b). CmapTools: A knowledge modeling and sharing environment. In A. J. Cañas, J. D. Novak \& F. M. González (Eds.), Concept maps: Theory, methodology, technology. Proceedings of the first international conference on concept mapping (Vol. I, pp. 125-133). Pamplona, Spain: Universidad Pública de Navarra.

Cañas, A. J., Hill, G., Granados, A., Pérez, C., \& Pérez, J. D. (2003a). The network architecture of CmapTools (Technical Report No. IHMC CmapTools 2003-01). Pensacola, FL: Institute for Human and Machine Cognition.

Cañas, A. J., Hill, G., \& Lott, J. (2003b). Support for constructing knowledge models in CmapTools (Technical Report No. IHMC CmapTools 2003-02). Pensacola, FL: Institute for Human and Machine Cognition.

Coffey, J. W., Carnot, M. J., Feltovich, P. J., Feltovich, J., Hoffman, R. R., Cañas, A. J., \& Novak, J. D. (2003a). A summary of literature pertaining to the use of concept mapping techniques and technologies for education and performance support (No. Technical Report submitted to the US Navy Chief of Naval Education and Training). Pensacola, FL: Institute for Human and Machine Cognition.

Coffey, J. W., \& Cañas, A. J. (2003). Leo: A learning environment organizer to support computer-mediated instruction. Journal for Educational Technology, 31(3).

Coffey, J. W., Cañas, A. J., Reichherzer, T., Hill, G., Suri, N., Carff, R., Mitrovich, T., \& Eberle, D. (2003b). Knowledge modeling and the creation of el-tech: A performance support system for electronic technicians. Expert Systems with Applications, 25(4), 483-492.

Coffey, J. W., Hoffman, R. R., Cañas, A. J., \& Ford, K. M. (2002). A concept-map based knowledge modeling approach to expert knowledge sharing. In M. Boumedine (Ed.), Proceedings of IKS 2002 - the IASTED international conference on information and knowledge sharing (pp. 212-217). Calgary, Canada: Acta Press.

Ford, K. M., Cañas, A. J., \& Coffey, J. W. (1993). Participatory explanation. In D. D. Dankel \& J. Stewman (Eds.), Proceedings of the sixth Florida artificial intelligence research symposium (pp. 111-115). Ft. Lauderadale, FL: FLAIRS.

Ford, K. M., Coffey, J. W., Cañas, A. J., Andrews, E. J., \& Turner, C. W. (1996). Diagnosis and explanation by a nuclear cardiology expert system. International Journal of Expert Systems, 9, 499-506.

Grayson, C. J., \& O'Dell, C. (1998). If we only knew what we know: The transfer of internal knowledge and best practice. New York, NY: The Free Press.

Hoffman, R. R., Coffey, J. W., \& Ford, K. M. (2000). A case study in the research paradigm of human-centered computing: Local expertise in weather forecasting. Report on the contract "human-centered system prototype". Washington, DC: National Technology Alliance.

Hoffman, R. R., Coffey, J. W., Novak, J. D., \& Cañas, A. J. (2005). Application of concept maps to web design and web work. In R. W. Proctor \& K.-P. L. Vu (Eds.), Handbook of human factors in web design (pp. 156-175). Mawah, NJ: Lawrence Erlbaum Associates.

IEEE. (2003). Proceedings of the seventh international conference on information visualization. Los Alamitos, CA: IEEE Computer Society Press.

Knowledge. (2004, November 21). Wikipedia: The free encyclopedia. Retrieved Nov. 21, 2004, from http://en.wikipedia.org/wiki/Knowledge 
Leake, D. B., Maguitman, A., \& Reichherzer, T. (2004a). Understanding knowledge models: Modeling assessment of concept importance in concept maps. In R. Alterman \& D. Kirsch (Eds.), Proceedings of the twenty-sixth annual conference of the cognitive science society (pp. 795-800). Mahwah, NJ: Lawrence Erlbaum.

Leake, D. B., Maguitman, A., Reichherzer, T., Cañas, A. J., Carvalho, M., Arguedas, M., \& Eskridge, T. (2004b). Googling from a concept map: Towards automatic conceptmap-based query formation. In A. J. Cañas, J. D. Novak \& F. M. González (Eds.), Concept maps: Theory, methodology, technology. Proceedings of the first international conference on concept mapping (Vol. I, pp. 409-416). Pamplona, Spain: Universidad Pública de Navarra.

Novak, J., Fleishmann, M., Strauss, W., Schneider, M., Wurst, M., Morik, K., \& Kunz, C. (2002). Augmenting the knowledge bandwidth and connecting heterogeneous expert communities through uncovering tacit knowledge. In Proceedings of the IEEE workshop on knowledge media networking (pp. 87): IEEE Computer Society.

Novak, J. D. (1977). A theory of education. Ithaca, NY: Cornell University Press.

Novak, J. D. (1998). Learning, creating, and using knowledge: Concept maps as facilitative tools in schools and corporations. Mahwah, NJ: Lawrence Erlbaum Associates.

Novak, J. D. (2003). Concept map about concept maps. Retrieved April 12, 2004, from http://pavo.coginst.uwf.edu/servlet/SBReadResourceServlet?rid=1064009710027_14 $83270340 \quad 27090 \&$ partName $=$ htmltext

Novak, J. D., \& Gowin, D. B. (1984). Learning how to learn. New York, NY: Cambridge University Press.

Spink, A., Wolfram, D., Jansen, B., \& Saracevic, T. (2001). The public and their queries. Journal of the American Society for Information Science and Technology, 52(3), 226-234.

Takeuchi, H., \& Nonaka, I. (2004). Hitotsubashi on knowledge management. Singapore, Asia: John Wiley \& Sons.

Tergan, S.-O. (2003). Managing knowledge with computer-based mapping tools. In D. Lassner \& C. M. Naught (Eds.), Proceedings of the ed-media 2003 world conference on educational multimedia, hypermedia \& telecommunication (pp. 2514-2517). Honolulu, HI: University of Honolulu.

Tiwana, A. (2000). The knowledge management toolkit. Upper Saddle River, NJ: Prentice Hall. Tufte, E. R. (1997). Visual explanations: Images and quantities, evidence and narrative. Cheshire, CN: Graphics Press.

Tufte, E. R. (2001). Visual display of quantitative information. Cheshire, CN: Graphics Press. 